\title{
CONTRIBUIÇÕES DA PLATAFORMA FOCO APRENDIZAGEM NO ENSINO DE LÍNGUA PORTUGUESA
}

\author{
DAYANE MARTIN SILVA' \\ ANA SÍLVIA MOÇO APARÍCIO" \\ I Secretaria de Educação do Estado de São Paulo (SEE-SP), São Paulo-SP, Brasil; \\ dayanemartinsilva@yahoo.com.br \\ II Universidade Municipal de São Caetano do Sul (USCS), São Caetano do Sul-SP, Brasil; \\ anaparicio@uol.com.br
}

\section{RESUMO}

Este trabalho investigou contribuições da Plataforma Foco Aprendizagem ao trabalho do professor de Língua Portuguesa e ao melhor desempenho dos alunos nas habilidades previstas pela Matriz de Avaliação Processual, implantada em 2016. O estudo é intervencionista, conduzido na própria prática do pesquisador/professor. O referencial teórico baseia-se na concepção dialógica da língua, de Bakhtin, e nas abordagens de ensino de gêneros textuais do Grupo de Didática de Línguas de Genebra. Os dados foram obtidos em turmas de $6^{\circ}$ ano de uma escola da Grande São Paulo. Os resultados evidenciam que o uso da plataforma contribuiu para o melhor desempenho dos alunos em todas as habilidades previstas, bem como para o trabalho do professor na realização de diagnósticos e intervenções mais individualizadas.

PALAVRAS-chaVe ENSINO DE LÍNGUA PORTUGUESA - AVALIAÇÃO DO RENDIMENTO ESCOLAR • CURRÍCULO SÃO PAULO • PLATAFORMA FOCO APRENDIZAGEM. 


\section{CONTRIBUCIONES DE LA PLATAFORMA ENFOQUE APRENDIZAJE EN LA ENSEÑANZA DE LA LENGUA PORTUGUESA}

\section{RESUMEN}

Este trabajo investigó contribuciones de la Plataforma Foco Aprendizagem al trabajo de los profesores de Lengua Portuguesa y al mejor desempeño de los alumnos en las habilidades previstas por la Matriz de Evaluación Procesal, implantada en 2016. El estudio es intervencionista, conducido por la propia práctica del investigador/profesor. El referente teórico se basa en la concepción dialógica del idioma, de Bakhtin, y en los abordajes de la enseñanza de géneros textuales del Grupo de Didáctica de Lenguas de Ginebra. Los datos se obtuvieron en grupos del $6^{\circ}$ año de una escuela de la Gran São Paulo. Los resultados ponen de manifiesto que el uso de la plataforma contribuyó para el mejor desempeño de los estudiantes en todas las habilidades previstas, así como para el trabajo del profesor en la realización de diagnósticos e intervenciones más individualizadas.

PALABRAS CLAVE ENSEÑANZA DE LA LENGUA PORTUGUESA • EVALUACIÓN DEL RENDIMIENTO ESCOLAR • CURRÍCULO SÃO PAULO • PLATAFORMA FOCO APRENDIZAGEM.

\section{CONTRIBUTIONS OF THE PLATAFORMA FOCO APRENDIZAGEM IN THE TEACHING OF THE PORTUGUESE LANGUAGE}

\section{ABSTRACT}

This study investigated contributions from the Plataforma Foco Aprendizagem, which provides data on students' performance on the assessments implemented by the state network of São Paulo, to the work of the Portuguese Language teacher and the better performance of students in the skills provided by the Matriz de Avaliação Processual, implemented in 2016. The study is interventionist, conducted in the researcher/teacher's own practice. The theoretical reference is based on the dialogical conception of language defended by Bakhtin and on the approaches to teaching textual genres of the Language Didactics Group of the University of Geneva. Data were obtained from $6^{\text {th }}$ grade classes at a school in Greater São Paulo. The results show that the use of the Plataforma contributed to the improvement of students' performance in all predicted abilities, as well as to the teacher's work in carrying out more individualized diagnoses and interventions.

KEYWORDS PORTUGUESE LANGUAGE TEACHING • ASSESSMENT OF SCHOOL PERFORMANCE • CURRICULUM SÃO PAULO • PLATAFORMA FOCO APRENDIZAGEM. 


\section{INTRODUÇÃO}

A Secretaria de Educação do Estado de São Paulo (SEE-SP), preocupada com os baixos índices de desempenho dos alunos da rede estadual, deu início, em 2008, ao programa denominado "São Paulo faz escola", que tem como principal objetivo unificar o currículo escolar de toda a rede pública estadual. Esse programa foi responsável pela implantação do currículo oficial do estado de São Paulo, composto por um conjunto de documentos e materiais didáticos de todas as disciplinas do currículo destinados aos anos finais do ensino fundamental e ensino médio. Entre esses materiais, destacam-se os “Cadernos", ainda utilizados em 2019, produzidos para professores e alunos com conteúdo baseado nas orientações do currículo.

Pautado pela perspectiva de um currículo voltado à construção de competências, o programa "São Paulo faz escola" estabelece habilidades e conteúdos considerados básicos e comuns a toda rede, com o compromisso de promover o bom desempenho dos alunos em avaliações externas, como o Sistema de Avaliação do Rendimento Escolar do Estado de São Paulo (Saresp); e, assim, atingir as metas indicadas por índices da educação, como o Índice de Desenvolvimento da Educação de São Paulo (Idesp). Esse índice considera os resultados do Saresp nas provas de Língua Portuguesa e Matemática, juntamente com o fluxo escolar, com o objetivo de fornecer um diagnóstico da qualidade de cada escola, indicando aspectos em que se precisa avançar, bem como a evolução da escola ano a ano.

Vale destacar também, no conjunto dessas ações, a publicação, em 2009, das Matrizes de Referência para a Avaliação (SÃO PAULO, 2009), elaboradas a partir das competências e habilidades apontadas no currículo, por disciplina e por série, com o intuito de vincular mais estreitamente currículo e avaliação.

Ocorre que os resultados da rede paulista obtidos após essas reformas não foram satisfatórios. Dados do Idesp de 2012 e 2013, por exemplo, evidenciam que, nos anos finais do ensino fundamental, os resultados foram menores em relação aos anos anteriores. Os índices específicos de Língua Portuguesa não são muito diferentes: os resultados mostram que, até 2013, nos três ciclos (anos iniciais, anos finais e ensino médio), o desempenho da maioria dos alunos não passa do nível considerado "básico", ou seja, demonstra domínio mínimo dos conteúdos, das competências e habilidades de cada ciclo (SÃO PAULO, 2015).

Um problema enfrentado pela SEE-SP é que os resultados das avaliações externas não vinham sendo considerados e discutidos suficientemente na escola para induzir estratégias de ensino voltadas ao desenvolvimento das habilidades e competências solicitadas nas avaliações. Bauer (2008), em sua pesquisa sobre o uso dos resultados do Saresp e a formação de professores, constatou que, embora supervisores de ensino e assistentes técnico-pedagógicos reconheçam a importância de se considerar os resultados das avaliações para a formação docente e reorientação pedagógica, 
seus depoimentos apontaram grande dificuldade das diretorias de ensino e equipes escolares ao se apropriar dos dados das avaliações e interpretá-los adequadamente, de forma a redirecionar e instrumentalizar as práticas pedagógicas em sala de aula. Outras pesquisas sobre o Saresp também apontam usos inadequados de seus resultados, como o treinamento dos alunos para a realização das provas (SILVA, 2006) e a instauração de rankings e competições entre as escolas (RODRIGUES, 2011).

A própria SEE-SP, certamente reconhecendo esses problemas e dificuldades, promoveu, em 2011, uma profunda reorganização de sua estrutura, atribuindo à Coordenadoria de Gestão da Educação Básica (CGEB) e à Coordenadoria de Informação, Monitoramento e Avaliação Educacional (Cima) a tarefa de implementar a Avaliação de Aprendizagem em Processo (AAP) nas escolas da rede pública estadual e, mais recentemente, em 2015, a Plataforma Foco Aprendizagem (PFA), uma ferramenta que disponibiliza aos professores de Língua Portuguesa e Matemática dados individuais e coletivos do rendimento dos alunos no Saresp e na AAP.

Resultados positivos alcançados em uma experiência como docente nos anos finais do ensino fundamental da rede estadual paulista, em um trabalho intensivo de recuperação de alunos em habilidades de Língua Portuguesa com o uso da Plataforma despertou-nos o interesse em investigar, em nossa pesquisa de mestrado profissional em educação, contribuições dessa ferramenta para a formação e o trabalho do professor de Língua Portuguesa e o melhor desempenho dos alunos na aprendizagem.

Neste artigo, evidenciamos o processo e os resultados dessa pesquisa, apontando como o uso e a interpretação dos resultados de avaliação de desempenho discente, oferecidos pela Plataforma, podem auxiliar o professor no planejamento e realização das intervenções nas aulas de Língua Portuguesa e, consequentemente, melhorar a aprendizagem dos alunos. Para tal, destacamos, inicialmente, concepções teórico-metodológicas que embasam o Currículo de Língua Portuguesa (CLP) oficial da rede estadual paulista. Na sequência, abordamos a AAP, destacando os seus objetivos e intenções, no contexto da atual política de monitoramento e avaliação educacional do estado de São Paulo, bem como a Plataforma Foco Aprendizagem, seus recursos e instrumentos de armazenamento e disponibilização de dados dos resultados educacionais. Por fim, apresentamos os procedimentos metodológicos da pesquisa, a descrição e análise dos dados obtidos na plataforma e as conclusões.

\section{CONCEPÇÕES TEÓRICO-METODOLÓGICAS DO CURRÍCULO OFICIAL DE LÍNGUA PORTUGUESA DO ESTADO DE SÃO PAULO}

O currículo oficial do estado de São Paulo, implementado em 2008 na rede, inspirado nas Diretrizes Curriculares Nacionais para o ensino médio (BRASIL, 1998a), 
está organizado em quatro áreas básicas do conhecimento, a saber: 1) Ciências da Natureza e suas tecnologias, englobando as disciplinas de Ciências, Biologia, Física e Química; 2) Matemática e suas tecnologias; 3) Ciências Humanas e suas tecnologias, envolvendo História, Geografia, Filosofia e Sociologia; 4) Linguagens, Códigos e suas tecnologias, envolvendo Língua Portuguesa, Língua Estrangeira Moderna Inglês ou Espanhol, Arte e Educação Física.

O currículo está voltado à construção de competências que, na visão de Berger Filho (s.d., p. 15), “[...] não pressupõe abandonar a transmissão dos conhecimentos nem a construção de novos conhecimentos; ao contrário, esses processos são indissociáveis na construção destas competências”. Competências são compreendidas pelo autor como:

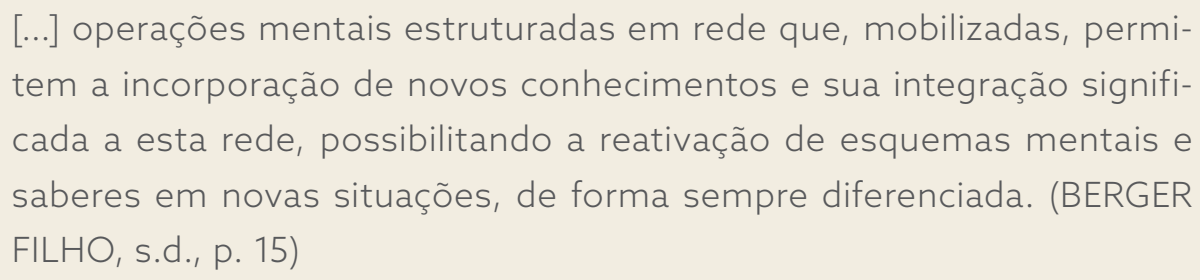

Nessa perspectiva de currículo, de acordo com Berger Filho (s.d.), a prática pedagógica está centrada não na transmissão de conhecimentos, e sim no processo de construção, apropriação e mobilização desses conhecimentos. Dessa forma, a construção de competências está associada aos conhecimentos que são construídos de modo significativo em dada situação.

Baseando-se nessa concepção, o currículo busca orientar as escolas a "[...] promover as competências indispensáveis ao enfrentamento dos desafios sociais, culturais e profissionais do mundo contemporâneo" (FINI, 2008, p. 8), seguindo seis princípios: 1) uma escola que também aprende; 2) o currículo como espaço de cultura; 3) as competências como referência; 4) prioridade para a competência da leitura e da escrita; 5) articulação das competências para aprender; e 6) articulação com o mundo do trabalho.

Tendo em vista tais princípios, o CLP, inspirado nas orientações dos Parâmetros Curriculares Nacionais (PCN) (BRASIL, 1998b), assume explicitamente a concepção dialógica de linguagem concebida por Bakhtin (1997) como lugar de interação humana, em elaboração constante por sujeitos históricos e sociais, constituindo enunciados orais e escritos variados em gêneros do discurso. Nesse sentido, o CLP defende o ensino da língua materna para e nas práticas sociais de uso da língua e privilegia o trabalho com os gêneros textuais/discursivos, afirmando a necessidade de compreensão de suas características linguísticas e discursivas, tanto na produção quanto na leitura de textos, para que os discentes sejam capazes de simbolizar suas experiências por meio da palavra, ao construir significados e produzir 
sentidos. Portanto, para o CLP, ao se ensinar e estudar a língua, é essencial reconhecer os recursos linguísticos que são utilizados por quem fala ou escreve para dizer o que diz em uma determinada situação de interação.

O texto do CLP (SÃO PAULO, 2011) para os anos finais do ensino fundamental, nosso foco de estudo, apresenta os conteúdos básicos distribuídos em quatro bimestres para cada série/ano, contemplando quatro eixos: "tipologias textuais", "gêneros textuais", "texto e discurso" e "texto e história”. No eixo das "tipologias textuais", de acordo com o documento, são estudadas as diferentes formas de organização dos textos (narração, exposição, argumentação, prescrição, etc.), com o objetivo de levar o aluno a compreender que diferentes gêneros de textos podem apresentar uma forma de organização semelhante. Por exemplo, uma fábula, uma crônica ou uma piada são gêneros diferentes que circulam em contextos também diferentes, mas que são organizados por uma mesma tipologia textual, a narração. Reconhecer esses aspectos é essencial para compreender e produzir textos, considerando as situações reais em que se realizam.

No eixo dos "gêneros textuais", como propõe o documento, são estudadas as funções sociocomunicativas dos textos, de forma que, em cada bimestre, são selecionados dois gêneros relacionados às tipologias textuais estudadas na série em questão, considerando que os gêneros podem ser compostos por mais de uma tipologia. Por exemplo, uma fábula é organizada pela tipologia narrativa, mas também pode ter sequências textuais argumentativas, injuntivas e descritivas. O objetivo desse eixo é que os alunos reconheçam os aspectos determinados pela situação de comunicação, tais como: os propósitos/intenções do texto, o público-alvo, o contexto de circulação, o suporte, etc.

No eixo "texto e discurso", de acordo com o documento, o texto é estudado de um ponto de vista mais amplo, isto é, considerando-se a esfera da atividade humana em que está inserido. $O$ intuito é que os alunos reconheçam que os gêneros textuais se relacionam diretamente aos valores sociais do contexto no qual são produzidos e/ ou circulam. O CLP seleciona para estudo quatro esferas discursivas: publicitária, jornalística, artística e política.

Por fim, o eixo "texto e história" envolve os três eixos anteriores, sendo o momento em que os alunos são "[...] convidados a refletir sobre valores sociais, políticos, econômicos, culturais, etc.”, os quais são "[...] materializados em textos de diversas tipologias e gêneros, construídos em diferentes situações de comunicação historicamente determinadas” (SÃO PAULO, 2011, p. 37).

Vale destacar que, no âmbito de todos esses eixos, os conteúdos também contemplam aspectos gramaticais da língua, tanto no que se refere às regras da norma padrão, com reflexão sobre as variedades linguísticas, quanto ao estudo das categorias gramaticais tal como tradicionalmente apresentadas em livros didáticos. 
Quanto à metodologia de ensino-aprendizagem dos conteúdos básicos da disciplina de Língua Portuguesa, o CLP inspira-se nos estudos de pesquisadores do Grupo de Didática de Línguas da Universidade de Genebra, especialmente Joaquim Dolz e Bernard Schneuwly (2004), que, com base em uma experiência de ensino de francês como língua materna na Suíça francófona, elaboraram uma proposta para o trabalho com os gêneros textuais na escola na perspectiva de progressão. Trata-se de uma organização de uma sequência de atividades que permitam a transformação gradual das capacidades dos alunos para dominar um gênero.

Como há uma grande diversidade de gêneros textuais, tornando-se impossível a sistematização de todos esses gêneros no ensino da língua, Dolz e Schneuwly (2004) optaram por um enfoque didático de agrupamentos de gêneros, em função das tipologias textuais que os organizam. Nesse modelo didático, foram estipuladas cinco tipologias e suas características: narrar (mimese de ação por meio da intriga), relatar (representação de experiências vividas, situadas no tempo), argumentar (sustentação, refutação e negociação de tomadas de posição), expor (apresentação textual de diferentes formas de saberes) e descrever ações (instruções e prescrições, regulação mútua de comportamentos).

Assim, os autores sugerem que se agrupem os gêneros por séries e que seja escolhido um de cada vez para ser trabalhado. Por exemplo, fazem parte do agrupamento do "narrar" os gêneros conto maravilhoso, fábula, lenda, piada, etc.; do agrupamento do argumentar, os gêneros artigo de opinião, carta de leitor, carta de reclamação, etc. Os agrupamentos, de acordo com Dolz e Schneuwly (2004), não são estanques uns em relação aos outros, e também não é possível classificar cada gênero de maneira absoluta em um dos agrupamentos propostos. No entanto, é possível definir, para cada um deles, algumas capacidades globais que se devem construir ao longo da escolaridade, de tal forma que um gênero pode ser abordado em diferentes níveis de exigência e dificuldade, de acordo com a série. Por exemplo, no agrupamento do "relatar", no $1^{\circ}, 2^{\circ}$ e $3^{\circ}$ ano, pode ser estudado o gênero relato de experiência vivida; no $4^{\circ}$ e $5^{\circ}$ ano, a notícia; no $6^{\circ}$ ano, o diário de bordo; no $7^{\circ}$ ano, a autobiografia; no $8^{\circ}$ e $9^{\circ}$ ano, a biografia de personalidades ou biografia literária.

O CLP, então, inspirado na proposta dos pesquisadores de Genebra, estabelece as seguintes premissas: no primeiro bimestre de todas as séries/anos, o eixo principal é o estudo de uma tipologia; no segundo bimestre, é o estudo de gêneros textuais que apresentem, predominantemente, a tipologia estudada no bimestre anterior; e no terceiro e quarto bimestre, são desenvolvidos projetos, um em cada bimestre, que envolvam os gêneros e as tipologias estudadas naquela série/ano, inserindo-os em uma perspectiva discursiva. O Quadro 1 ilustra como esses eixos estão organizados no CLP. 
QUADRO 1 - Eixos de organização dos conteúdos

\begin{tabular}{|c|c|c|c|c|c|}
\hline SÉRIE & $\mathbf{6}^{\circ}$ ANO & $7^{\circ}$ ANO & $8^{\circ}$ ANO & \multicolumn{2}{|c|}{$\mathbf{9}^{\circ}$ ANO } \\
\hline $\begin{array}{c}\text { AGRUPAMENTOS } \\
\text { TIPOLÓGICOS }\end{array}$ & NARRAR & RELATAR & DESCREVER & EXPOR & ARGUMENTAR \\
\hline GÊNEROS TEXTUAIS & $\begin{array}{c}\text { Crônica } \\
\text { narrativa, } \\
\text { narrativa de } \\
\text { enigma e letra } \\
\text { de música }\end{array}$ & $\begin{array}{c}\text { Relato de } \\
\text { experiência, } \\
\text { notícia e } \\
\text { autobiografia }\end{array}$ & $\begin{array}{c}\text { Anúncio } \\
\text { publicitário, } \\
\text { regras de jogo e } \\
\text { receitas }\end{array}$ & $\begin{array}{c}\text { Artigo de } \\
\text { divulgação } \\
\text { científica }\end{array}$ & $\begin{array}{c}\text { Artigo de opinião } \\
\text { e carta do leitor }\end{array}$ \\
\hline DISCURSO & Artístico & Jornalístico & Publicitário & Político \\
\hline
\end{tabular}

Fonte: Elaborado pelas autoras com base no CLP (SÃO PAULO, 2011, p. 46-77).

De acordo com o CLP, tal organização busca integrar três aspectos essenciais dos estudos contemporâneos de língua: os agrupamentos tipológicos, os gêneros e o discurso. O CLP propõe que esses aspectos estejam integrados nas chamadas "situações de aprendizagem". Ocorre que os Cadernos, ao operacionalizarem essa proposta do CLP, apresentam sequências didáticas previamente definidas, com atividades também prontas, que, diferentemente da proposta de sequência didática dos pesquisadores de Genebra, não possibilitam a diferenciação no ensino, uma vez que não permitem “[...] ao professor avaliar as capacidades já adquiridas e ajustar as atividades e os exercícios previstos na sequência às possibilidades e dificuldades reais de uma turma" (DOLZ; SCHNEUWLY, 2004, p. 98).

Outro aspecto que merece destaque, no que se refere às "situações de aprendizagem” prescritas nos Cadernos, é que as atividades de leitura, produção escrita e análise linguística não são consideradas e trabalhadas de modo articulado em torno dos gêneros de texto, tal como propõem Dolz e Schneuwly (2004), por meio do desenvolvimento de sequências didáticas de gêneros textuais.

Pesquisadores da área de ensino e aprendizagem do português como língua materna, tais como Bunzen e Rojo (2005), Nascimento (2009), Aparício (2010), Gonçalves (2011), entre outros, defendem que, numa abordagem de ensino de língua materna, orientada pela concepção de linguagem como forma de interação (BAKHTIN, 1997), as práticas didáticas de leitura, produção escrita e conhecimentos linguísticos são planejadas e trabalhadas de forma articulada, tendo o texto ou o gênero como categorias organizadoras dessas práticas.

Vale ressaltar que outras pesquisas que analisaram o material do programa "São Paulo faz escola" também apontam o aspecto normalizador e prescritivo dos Cadernos. Pereira (2011), por exemplo, aponta que a implementação dos Cadernos padroniza a forma de aprendizagem dos alunos e a prática do professor, o que acaba por desestimular ambos.

Outro ponto que merece ser destacado em relação ao CLP é que, embora o documento afirme uma preocupação com as novas tecnologias da comunicação e 
informação e com o trabalho com os textos multimodais e multissemióticos, como vemos em "[...] aqui nos interessam, por exemplo, as novas tecnologias de informação, o hipertexto, os CD-ROMs, as páginas da web e as outras expressões artísticas como a pintura, a escultura, a fotografia, etc.” (SÃO PAULO, 2011, p. 28), percebemos que o documento não contempla tais textos. Nem mesmo os gêneros orais formais públicos (debate regrado, exposição oral, entrevistas, etc.) são mencionados. O que fica evidente é que a organização do documento contempla gêneros textuais escritos.

Percebemos ainda que o CLP não evidencia a ideia de progressão em espiral proposta por Dolz e Schneuwly (2004), com base nos agrupamentos de gêneros, de forma que cada agrupamento seja estudado em todos os anos, por meio dos gêneros que o compõem. Isto é, a cada ano seriam trabalhadas determinadas dimensões de um gênero que vão se aprofundando nos anos subsequentes, para que, ao final do ciclo, várias dimensões de gêneros de uma mesma tipologia tenham sido contempladas. Como apresentamos no Quadro 1, gêneros do grupo do "narrar" são estudados no $6^{\circ}$ ano; do "relatar", no $7^{\circ}$ ano; do "descrever", no $8^{\circ}$ ano; e do "expor e argumentar", no $9^{\circ}$ ano. Portanto, não é possível observar no CLP essa progressão denominada por Coll (1992) de "intraciclo", em que os objetivos e conteúdos são organizados e distribuídos ao longo das séries de um nível de ensino, em uma perspectiva espiral, de tal forma que objetivos e conteúdos semelhantes sejam abordados em níveis de complexidade cada vez maior ao longo das séries.

Contudo, é possível constatar, no CLP, certa progressão em uma mesma série, como pudemos verificar nos conteúdos e habilidades do $6^{\circ}$ ano, em que a tipologia narrativa é estudada ao longo de todos os bimestres em várias dimensões. No Quadro 2, selecionamos alguns conteúdos e habilidades para exemplificar esse tipo de progressão.

\section{QUADRO 2 - Exemplo de progressão no currículo do $6^{\circ}$ ano}

\begin{tabular}{|c|c|c|}
\hline $\mathbf{1}^{\circ}$ BIMESTRE & $\mathbf{2}^{\circ}$ BIMESTRE & $\mathbf{3}^{\circ} \mathbf{E} \mathbf{4}^{\circ}$ BIMESTRE \\
\hline $\begin{array}{c}\text { Traços característicos de textos } \\
\text { narrativos: enredo, personagem, foco } \\
\text { narrativo, tempo, espaço. }\end{array}$ & $\begin{array}{c}\text { Estudo da narratividade em diferentes } \\
\text { gêneros. } \\
\text { Gênero textual crônica narrativa. } \\
\text { Gênero textual letra de música. }\end{array}$ & $\begin{array}{c}\text { Estudo de tipologia e gêneros } \\
\text { narrativos articulados por projetos. }\end{array}$ \\
\hline HABILIDADE & HABILIDADE & HABILIDADE \\
\hline $\begin{array}{c}\text { Inferir e reconhecer elementos da } \\
\text { narrativa. }\end{array}$ & $\begin{array}{c}\text { Reconhecer características do gênero } \\
\text { crônica narrativa. }\end{array}$ & $\begin{array}{c}\text { Reconhecer o processo de composição } \\
\text { textual como um conjunto de ações } \\
\text { interligadas. }\end{array}$ \\
\hline
\end{tabular}

Fonte: Elaborado pelas autoras com base no CLP da rede estadual de São Paulo (SÃO PAULO, 2011, p. 46-53).

Como podemos observar no Quadro 2, com relação ao estudo da tipologia narrativa, no primeiro bimestre são trabalhados elementos da narrativa; no segundo, 
são estudados esses elementos em determinados gêneros. Já no terceiro e quarto bimestres, o objetivo é estudar os diferentes elementos que compõem os gêneros de textos narrativos, considerando a articulação de aspectos linguísticos e discursivos na composição dos textos uma dimensão bem mais complexa do que a estudada no primeiro bimestre.

Em suma, entendemos que o CLP é orientado pela perspectiva que, desde os anos 1980, vem sendo defendida pelos estudiosos da linguagem que trazem contribuições para o ensino da língua portuguesa no Brasil, tais como Geraldi (1984), Marcuschi (2008), Rojo (2000) e Soares (1998). Essa perspectiva, já defendida pelos PCN, elege os gêneros de texto como objeto principal de ensino da língua e propõe uma nova abordagem para o ensino de gramática baseada na atividade de análise e reflexão sobre a língua, de modo que as práticas de leitura, de produção oral e escrita e de análise linguística sejam realizadas em sala de aula de maneira integrada por meio do estudo de textos autênticos que circulam socialmente.

Além disso, embora os autores de Genebra não tenham sido indicados nas referências do documento, a abordagem metodológica de agrupamento de gêneros em tipologias está presente no CLP, ainda que não seja evidenciada a progressão tal como proposta pelos genebrinos.

De qualquer forma, essas mudanças demandam uma transformação radical do trabalho do professor em sala de aula, e, para isso, a SEE-SP, desde 2008, passou a instruir professores e coordenadores, com orientações técnicas em encontros presenciais, videoconferências e cursos de atualização a distância. Tendo em vista um melhor acompanhamento desse trabalho, em 2011, a SEE-SP deu início a uma política de monitoramento e avaliação educacional para acompanhar e orientar a melhoria na qualidade do ensino da rede. Uma das ações nessa direção é a implementação da Avaliação da Aprendizagem em Processo e a Plataforma Foco Aprendizagem, abordadas a seguir.

\section{AVALIAÇÃO DA APRENDIZAGEM EM PROCESSO E A PLATAFORMA FOCO APRENDIZAGEM}

Iniciamos a discussão deste item esclarecendo que temos ciência das inúmeras críticas de pesquisadores da área da educação - podemos citar algumas pesquisas mais atuais, como Carvalho (2014), Pinto (2016) e Prado (2016) - ao caráter controlador e fiscalizador das avaliações em larga escala, destacando que pouco contribuem para a construção da autonomia docente proclamada nos discursos oficiais. No caso do estado de São Paulo, as críticas também recaem sobre a utilização dos resultados das avaliações para o recebimento de bônus de mérito pela equipe escolar (PACCOLA, 2012). 
Entretanto, ressaltamos que esse não é o foco de nosso trabalho, pois buscamos compreender de que maneira a análise dos resultados das avaliações podem contribuir para reorientar e planejar a prática pedagógica. Acreditamos que as avaliações, mesmo que não sejam pensadas e utilizadas como instrumentos essencialmente formativos, oferecem um diagnóstico das habilidades e competências dos estudantes e, portanto, da qualidade da educação oferecida pelas escolas.

Como bem defendem Silva et al. (2013, p. 77), “[...] uma política de avaliação vai muito além da realização de provas, compilação e análise dos dados, e a divulgação dos resultados aferidos em relatórios e outros materiais destinados às escolas”. Esses autores investigaram os diferentes usos de avaliações externas por quatro redes públicas de ensino e destacaram o fato de três delas desenvolverem políticas próprias de avaliação, com autonomia para estabelecer períodos, anos e disciplinas a serem avaliados, bem como as formas de divulgação e uso dos resultados. Nessa investigação, os pesquisadores evidenciaram diferentes possibilidades de uso das avaliações e de seus resultados nas redes analisadas e o quanto esse trabalho pode contribuir para o aprimoramento das ações/intervenções da equipe gestora e dos professores nas escolas.

É, pois, nessa perspectiva que a AAP foi implantada na rede estadual paulista desde 2011 como uma política própria da SEE-SP de avaliação diagnóstica das disciplinas de Língua Portuguesa e Matemática. Inicialmente, era realizada a cada semestre, no $6^{\circ}$ ano do ensino fundamental e na $1^{\mathrm{a}}$ série do ensino médio. Gradativamente, a AAP passou a ser realizada em todos os anos finais do ensino fundamental e em todas as séries do ensino médio, bimestralmente. Mais recentemente, a AAP passou a ser realizada também nos anos iniciais do ensino fundamental, articulada ao Programa Ler e Escrever.

De acordo com documento da SEE-SP,

[...] essa ação, fundamentada no Currículo do estado de São Paulo, tem como objetivo fornecer indicadores qualitativos do processo de aprendizagem do educando, a partir de habilidades prescritas no currículo. Dialoga com as habilidades contidas no SARESP, SAEB, ENEM e tem se mostrado bem avaliada pelos educadores da rede estadual. Propõe o acompanhamento da aprendizagem das turmas e do aluno de forma individualizada, por meio de um instrumento de caráter diagnóstico. Objetiva apoiar e subsidiar os professores de Língua Portuguesa e de Matemática que atuam nos anos finais do Ensino Fundamental e no Ensino Médio da Rede Estadual de São Paulo, na elaboração de estratégias para reverter desempenhos insatisfatórios, inclusive em processos de recuperação. (SÃO PAULO, 2014, p. 2)

Tendo isso em vista, e embasada até 2015 na Matriz de Avaliação do Saresp (SÃO PAULO, 2009), a AAP de Língua Portuguesa é composta por uma prova com questões 
de múltipla escolha (o número de questões varia a cada edição, sendo geralmente entre 8 e 15) e uma produção textual, abrangendo os conteúdos e habilidades propostos no currículo e nos Cadernos. As provas são elaboradas pelos órgãos centrais da SEE-SP e aplicadas pelos próprios professores em suas turmas, em datas predeterminadas, com o objetivo principal de acompanhar as aprendizagens e as dificuldades diagnosticadas.

As provas da AAP de Língua Portuguesa seguem modelo semelhante ao das outras avaliações externas, como a Prova Brasil, porém manifestam um caráter mais formativo do que as avaliações externas, uma vez que seus resultados podem ser trabalhados logo após a sua realização. Já no caso do Saresp, por exemplo, os resultados são conhecidos somente no ano posterior à sua realização.

O que se espera, portanto, com a AAP, é que se possibilite aos professores uma análise mais precisa do que o aluno já domina e do que ainda necessita aprender, identificando as defasagens específicas dos estudantes e/ou turmas para que possam planejar e desenvolver ações pedagógicas mais assertivas, aproximando-se de um ensino considerado personalizado ou "ensino sob medida", a fim de atender às necessidades individuais dos alunos, inclusive nos processos de recuperação (MILIBAND, 2006, p. 24).

Em seu processo de implementação, a AAP sofreu e ainda vem sofrendo transformações e ajustes. Uma alteração significativa ocorreu em 2016, quando foi elaborada a Matriz de Avaliação Processual (MAP) de todas as disciplinas do Currículo. Assim, a partir da $11^{\mathrm{a}}$ edição da AAP, as questões passaram a ter como referência não mais as habilidades da Matriz de Avaliação do Saresp, e sim as habilidades contidas na MAP. A esse respeito, o documento da MAP ressalta que,

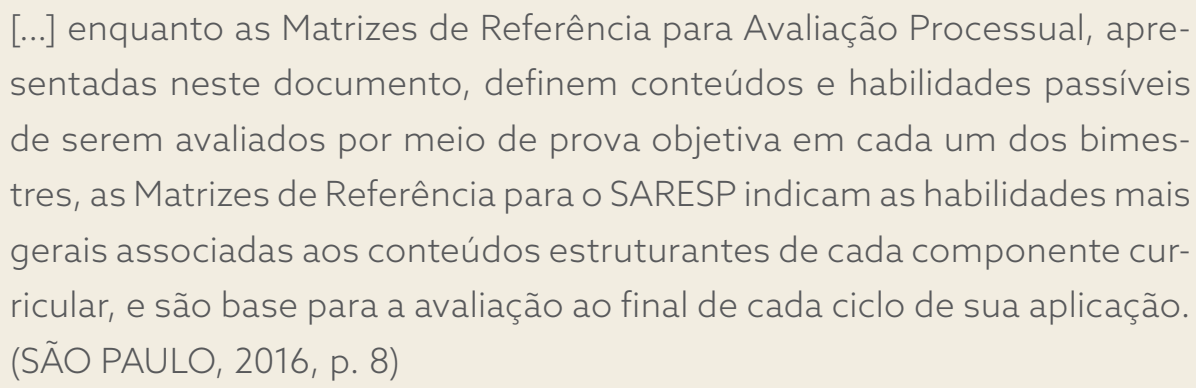

A MAP de Língua Portuguesa apresenta cada ano subdividido em quatro bimestres, todos eles organizados em três partes: 1) conteúdos: são os mesmos contidos no currículo e nos Cadernos; 2) situação de aprendizagem/competências e habilidades: são as mesmas situações de aprendizagem dos Cadernos e são referenciadas pelo número em que constam dos Cadernos e as respectivas habilidades; 3) avaliação processual/habilidades: são elencadas as habilidades que serão consideradas na AAP, subdivididas em "aspectos textuais" e "aspectos linguísticos”. 
Sendo assim, desde 2016 até o momento atual, as questões da AAP são elaboradas com base nessa matriz, e, para o melhor acompanhamento dos resultados das avaliações (Saresp e AAP), também foi criada a ferramenta Plataforma Foco Aprendizagem, um portal da SEE-SP disponibilizado em 2015 com a principal finalidade de reforçar a relação entre currículo, avaliação e gestão da aprendizagem. A partir de 2016, além dos dados do Saresp, a Plataforma passou a integrar os resultados das AAP, Idesp e materiais de apoio para os educadores.

Com essa ferramenta, os professores da rede estadual de São Paulo passaram a ter acesso aos resultados dessas avaliações por ano e turmas em gráficos e tabelas que indicam as potencialidades e as fragilidades nas habilidades de Língua Portuguesa e Matemática. A PFA está disponível para cada docente em exercício na rede na página da Secretaria Digital, por meio de login e senha, sendo possível visualizar vários aspectos essenciais para a análise pelo professor.

Uma das seções da plataforma dá acesso ao relatório de desempenho e resultados de análise da avaliação por questão, em todas as séries/anos da escola. Além disso, é possível fazer uma análise mais detalhada do ano/série, com informações sobre o número de participantes na prova, o número e o percentual de acertos por turma e por aluno. Se o professor tem duas turmas de $6^{\circ}$ ano, por exemplo, pode comparar o desempenho geral de ambas aos percentuais de acertos na rede estadual, como também o desempenho individualizado de cada aluno.

Outros dados oferecidos pela PFA são referentes às questões com mais erros ou acertos e o nível de dificuldade de cada questão (fácil, médio, difícil). Com esses dados, o professor pode organizar os agrupamentos produtivos em suas turmas, buscando reunir alunos com domínios diferenciados nas habilidades. Tais informações podem ser visualizadas no formato de gráfico de colunas e em escala de cores correspondente às dificuldades.

Ao clicar em uma determinada questão, é possível visualizar seu texto-base, as alternativas e a habilidade que deve ser mobilizada para respondê-la. A partir de tais informações, o professor pode verificar e analisar o porquê de os alunos terem assinalado tal alternativa, o que contribui para que faça um diagnóstico da turma em relação às habilidades e crie meios de intervir de forma mais assertiva.

Além desses, a Plataforma ainda oferece muitos outros recursos e informações sistematizadas que permitem ao professor identificar e analisar o desempenho dos alunos e as competências e as habilidades que devem ser priorizadas para o planejamento e realização das intervenções em sala de aula. 
PROCEDIMENTOS METODOLÓGICOS DA PESQUISA E ANÁLISE DOS DADOS DA PLATAFORMA FOCO APRENDIZAGEM

Esta é uma pesquisa aplicada, caracterizada por Gatti (2014) como pesquisa engajada, visto que a realidade empírica é o ponto de partida e o ponto de chegada da investigação. Esse tipo de trabalho, segundo a autora, problematiza situações/impasses socioeducacionais concretos, com vistas a evidenciar fatos específicos pela compreensão de situações localizadas. Dessa forma, realizamos uma intervenção, em nossa própria prática, em três turmas de $6^{\circ}$ ano em uma escola onde atuamos como professoras de Língua Portuguesa. Nos termos de Ponte (2002, p. 11),

\footnotetext{
A investigação sobre a sua prática é, por consequência, um processo fundamental de construção do conhecimento sobre essa mesma prática e, portanto, uma actividade de grande valor para o desenvolvimento profissional dos professores que nela se envolvem activamente. E, para além dos professores envolvidos, também as instituições educativas a que eles pertencem podem se beneficiar fortemente pelo facto dos seus membros se envolverem neste tipo de actividade, reformulando as suas formas de trabalho, a sua cultura institucional, o seu relacionamento com o exterior e até os seus próprios objectivos.
}

Com base nessa perspectiva, o processo de geração e análise dos dados da nossa pesquisa seguiu os seguintes procedimentos:

1) Levantamento, na PFA, dos dados de desempenho dos 91 alunos das três turmas de $6^{\circ}$ ano, na AAP diagnóstica realizada no início do $6^{\circ}$ ano e na AAP do primeiro bimestre. Esses dados nos ajudaram a diagnosticar as aprendizagens e dificuldades iniciais dos alunos do $6^{\circ}$ ano para elaborarmos o planejamento e a realização da primeira intervenção em sala de aula.

2) Levantamento na PFA dos dados de desempenho dos alunos na AAP do segundo bimestre para identificar e analisar os resultados após a primeira intervenção e proceder ao planejamento e realização da segunda intervenção.

3) Levantamento na PFA dos dados de desempenho dos alunos na AAP do terceiro bimestre para identificar e analisar os resultados após a segunda intervenção.

4) Análise, à luz do referencial teórico da pesquisa, do conjunto de dados de todo esse processo, que foi gravado em áudio e posteriormente transcrito.

Inicialmente, levantamos e analisamos os resultados da AAP diagnóstica, realizada pelos alunos que ingressaram no $6^{\circ}$ ano em fevereiro de 2018, cujas habilidades foram referentes à Matriz de Avaliação Processual do $5^{\circ}$ ano. A prova foi composta por oito questões, sendo quatro consideradas de nível fácil, duas de nível médio e duas de nível difícil, contemplando seis habilidades referentes ao $5^{\circ}$ ano. Os gêneros 
dos textos-base das questões foram fábula, tirinha, anedota, notícia e crônica narrativa. Com base nos dados fornecidos pela PFA sobre o resultado dessa primeira AAP, elaboramos o quadro a seguir.

\section{QUADRO 3 - Desempenho na AAP Diagnóstica'}

\begin{tabular}{|c|c|c|c|c|}
\hline HABILIDADE & QUESTÃO & NÍVEL & GÊNERO & ACERTOS \\
\hline \multirow{2}{*}{$\begin{array}{l}\text { Reconhecer marcas linguísticas em um texto do ponto de } \\
\text { vista do léxico, da morfologia ou da sintaxe. }\end{array}$} & Q2 & Médio & Fábula & $64 \%$ \\
\hline & Q8 & Difícil & $\begin{array}{l}\text { Crônica } \\
\text { narrativa }\end{array}$ & $65 \%$ \\
\hline $\begin{array}{l}\text { Estabelecer relações lógico-discursivas presentes no } \\
\text { texto por meio de elementos de referenciação. }\end{array}$ & Q4 & Difícil & Anedota & $65 \%$ \\
\hline \multirow[b]{2}{*}{$\begin{array}{l}\text { Inferir o sentido de uma palavra ou expressão em um } \\
\text { texto. }\end{array}$} & Q1 & Fácil & Fábula & $79 \%$ \\
\hline & Q5 & Médio & $\begin{array}{l}\text { Tirinha/ } \\
\text { Fábula }\end{array}$ & $80 \%$ \\
\hline $\begin{array}{l}\text { Reconhecer o efeito de sentido produzido pela exploração } \\
\text { de recursos gráficos (pontuação e outras notações) em } \\
\text { um texto. }\end{array}$ & Q7 & Fácil & $\begin{array}{l}\text { Crônica } \\
\text { narrativa }\end{array}$ & $85 \%$ \\
\hline Localizar informação explícita em um texto. & Q6 & Fácil & Notícia & $90 \%$ \\
\hline $\begin{array}{l}\text { Estabelecer relações de causa e consequência, entre } \\
\text { partes e/ou elementos de um texto. }\end{array}$ & Q3 & Fácil & Fábula & $92 \%$ \\
\hline
\end{tabular}

Fonte: Elaborado pelas autoras com base nos dados da PFA.

Como podemos observar no Quadro 3 acima, os alunos apresentam desempenho mais baixo (64\% e 65\%) em duas habilidades, solicitadas em duas questões de nível difícil e em uma questão de nível médio. Uma dessas habilidades é "Reconhecer marcas linguísticas em um texto do ponto de vista do léxico, da morfologia ou da sintaxe”, a qual se refere ao eixo da prática de análise linguística contextualizada, demandando do aluno o reconhecimento do uso de recursos linguísticos e gramaticais na construção do texto para veicular determinadas significações e efeitos de sentido pretendidos pelo autor (APARÍCIO, 2010). Entre os 91 alunos, 60 acertaram a resposta dessa questão, e 31 a erraram. Fazendo a análise das alternativas indicadas pelos alunos que erraram, foi possível identificar que o erro ocorreu pelo fato de os alunos não considerarem o contexto, isto é, não relacionarem as informações explícitas e implícitas do texto.

Com relação à outra habilidade em que os alunos não apresentaram bom desempenho (65\%), "Estabelecer relações lógico-discursivas presentes no texto por meio de elementos de referenciação", observamos que a dificuldade está na identificação da relação entre um elemento do texto e seu referente, ou seja, uma questão de coesão textual (KOCH, 2003).

1 Consideramos, conjuntamente, os dados de desempenho dos 91 alunos das três turmas de $6^{\circ}$ ano, uma vez que todos os estudantes realizaram as mesmas provas e desenvolveram as mesmas atividades interventivas realizadas pela professora. 
Em síntese, verificamos que as dificuldades apresentadas pelos alunos na AAP diagnóstica são, sobretudo, referentes à compreensão leitora e a aspectos de textualização em diferentes gêneros textuais escritos. Esses são indícios da necessidade de desenvolver, na intervenção, um trabalho que contemple tais aspectos.

A prova da AAP do primeiro bimestre, realizada pelos alunos em maio de 2018, tendo por referência a Matriz de Aprendizagem Processual do primeiro bimestre do $6^{\circ}$ ano, foi composta por 12 questões (4 consideradas de nível fácil, 4 de nível médio e 4 de nível difícil), contemplando 6 habilidades, sendo 2 questões para cada habilidade. Os gêneros dos textos-base das questões foram: trecho de romance, lenda, piada e conto. Com base nos dados fornecidos pela PFA sobre o resultado da AAP do primeiro bimestre, elaboramos o quadro a seguir.

\section{QUADRO 4 - Desempenho na AAP do primeiro bimestre}

\begin{tabular}{|c|c|c|c|c|}
\hline HABILIDADE & QUESTÃO & NÍVEL & GÊNERO & ACERTOS \\
\hline \multirow{2}{*}{$\begin{array}{l}\text { Localizar itens de informação explícita, } \\
\text { distribuídos ao longo do texto. }\end{array}$} & Q6 & Médio & Verbete & $58 \%$ \\
\hline & Q11 & Médio & Conto & $66 \%$ \\
\hline \multirow{2}{*}{$\begin{array}{l}\text { Identificar relações entre segmentos de um texto } \\
\text { a partir de substituição por forma pronominal, } \\
\text { substantivo e sinonímia. }\end{array}$} & Q8 & Fácil & Verbete & $68 \%$ \\
\hline & Q4 & Difícil & Trecho de romance & $49 \%$ \\
\hline \multirow{2}{*}{$\begin{array}{l}\text { Reconhecer aspectos linguísticos (pontuação) em } \\
\text { funcionamento em um texto. }\end{array}$} & Q1 & Fácil & $\begin{array}{l}\text { Trecho de romance/ } \\
\text { Piada }\end{array}$ & $70 \%$ \\
\hline & Q2 & Médio & Piada & $75 \%$ \\
\hline \multirow{2}{*}{$\begin{array}{l}\text { Identificar aspectos linguísticos (substantivo, } \\
\text { adjetivo, verbo e advérbio) em funcionamento em } \\
\text { um texto. }\end{array}$} & Q9 & Médio & Trecho de romance & $75 \%$ \\
\hline & Q12 & Difícil & Conto & $17 \%$ \\
\hline \multirow{2}{*}{$\begin{array}{l}\text { Reconhecer os elementos da narrativa } \\
\text { (personagem, enredo, tempo, espaço ou foco } \\
\text { narrativo) em um texto. }\end{array}$} & Q7 & Fácil & Verbete & $76 \%$ \\
\hline & Q10 & Difícil & Conto & $49 \%$ \\
\hline \multirow{2}{*}{$\begin{array}{l}\text { Estabelecer relações entre textos verbais e/ou } \\
\text { textos não verbais. }\end{array}$} & Q5 & Fácil & Verbete & $86 \%$ \\
\hline & Q3 & Difícil & Trecho de romance & $17 \%$ \\
\hline
\end{tabular}

Fonte: Elaborado pelas autoras com base nos dados da PFA.

Como podemos observar no Quadro 4, em geral, os alunos tiveram um bom desempenho (entre $68 \%$ e $86 \%$ ) em todas as questões de nível fácil. O mesmo ocorre com as habilidades de nível médio, em que os alunos tiveram desempenho entre 66\% e 75\%, com exceção da questão 6 (58\%), cuja habilidade é "Localizar itens de informação explícita”. Ao analisarmos a questão, percebemos que tal fato pode ser explicado porque a questão se refere a dois textos-base sobre a mesma temática, o que pode ter sido um dos fatores que confundiram os alunos, levando-os ao erro. Já o menor desempenho dos alunos é verificado nas quatro questões de nível "difícil", sendo que o pior resultado (17\%) está nas habilidades "Estabelecer relações entre textos verbais e/ou textos não verbais" (questão 3) e "Identificar aspectos linguísticos (substantivo, adjetivo, verbo e advérbio) em funcionamento em um texto" (questão 
12). No caso da questão 3, o que se espera do aluno é que interprete e relacione dois textos verbais: um trecho de romance e uma piada. Cabe ao leitor, portanto, associar ambos os textos e compreender suas relações e especificidades.

A questão 12, que também teve baixo índice de acerto (17\%), requer uma habilidade que envolve a análise linguística. Nesse caso, é importante que o leitor saiba identificar a função de um termo gramatical no texto. Trata-se de uma questão que envolve não apenas o conhecimento da classe gramatical de uma palavra, mas também a compreensão da função do termo no texto.

Além da análise do desempenho dos alunos nessa AAP do primeiro bimestre, verificamos que os gêneros textuais contemplados na prova (trecho de romance, lenda, piada, conto, verbete) não correspondem exatamente aos gêneros trabalhados no Caderno do primeiro bimestre do $6^{\circ}$ ano (fábula, conto, trechos de narrativa maravilhosa) e tampouco aos propostos no CLP (crônica narrativa, narrativa de enigma e letra de música). Embora todos esses gêneros sejam, em sua maioria, da ordem do narrar, há especificidades de cada um que necessitam ser estudadas em sala de aula nas práticas de leitura e produção de textos e análise linguística. Sendo assim, percebemos que os conteúdos da AAP do primeiro bimestre não estão articulados adequadamente ao CLP e aos Cadernos.

Em síntese, considerando as duas avaliações iniciais (AAP diagnóstica e AAP do primeiro bimestre), organizamos as dificuldades apresentadas pelos alunos em quatro categorias, conforme o Quadro 5 a seguir.

\section{QUADRO 5 - Habilidades com menor desempenho pelos alunos nas três primeiras avaliações}

\begin{tabular}{|c|c|c|c|}
\hline CATEGORIA & CONCEITO & HABILIDADES & AVALIAÇÃo \\
\hline \multirow{2}{*}{$\begin{array}{l}\text { Informações } \\
\text { explícitas }\end{array}$} & \multirow{2}{*}{$\begin{array}{l}\text { Informações presentes na } \\
\text { superfície do texto. }\end{array}$} & $\begin{array}{l}\text { Localizar itens de informação explícita } \\
\text { distribuídos ao longo do texto. }\end{array}$ & $\begin{array}{l}\text { AAP diagnóstica } \\
\text { AAP } 1^{\circ} \text { bimestre }\end{array}$ \\
\hline & & $\begin{array}{l}\text { Reconhecer os elementos da narrativa em } \\
\text { um texto. }\end{array}$ & $\begin{array}{l}\text { AAP diagnóstica } \\
\text { AAP } 1^{\circ} \text { bimestre }\end{array}$ \\
\hline \multirow{3}{*}{ Inferência } & \multirow{3}{*}{$\begin{array}{l}\text { Processo cognitivo de construção } \\
\text { de sentidos, por meio da } \\
\text { articulação de pistas linguísticas } \\
\text { do texto, das características } \\
\text { da situação comunicativa e de } \\
\text { conhecimentos prévios do leitor. }\end{array}$} & $\begin{array}{l}\text { Inferir informação implícita (opinião ou } \\
\text { tema/assunto principal) em um texto. }\end{array}$ & AAP diagnóstica \\
\hline & & $\begin{array}{l}\text { Estabelecer relações entre textos verbais } \\
\text { e/ou textos não verbais. }\end{array}$ & AAP $1^{\circ}$ bimestre \\
\hline & & $\begin{array}{l}\text { Reconhecer os elementos da narrativa em } \\
\text { um texto. }\end{array}$ & $\begin{array}{l}\text { AAP diagnóstica } \\
\text { AAP } 1^{\circ} \text { bimestre }\end{array}$ \\
\hline Referenciação & $\begin{array}{l}\text { Diversas formas de introdução } \\
\text { no texto de novos elementos ou } \\
\text { referentes. }\end{array}$ & $\begin{array}{c}\text { Estabelecer relações lógico-discursivas } \\
\text { presentes no texto por meio de elementos } \\
\text { de referenciação. }\end{array}$ & $\begin{array}{l}\text { AAP diagnóstica } \\
\text { AAP } 1^{\circ} \text { bimestre }\end{array}$ \\
\hline \multirow{2}{*}{$\begin{array}{l}\text { Análise } \\
\text { linguística/ } \\
\text { Gramática } \\
\text { contextualizada }\end{array}$} & \multirow{2}{*}{$\begin{array}{c}\text { Análise e reflexão sobre a língua em } \\
\text { contextos de uso, em textos orais } \\
\text { ou escritos. }\end{array}$} & $\begin{array}{l}\text { Reconhecer marcas linguísticas em um } \\
\text { texto do ponto de vista do léxico, da } \\
\text { morfologia ou da sintaxe. }\end{array}$ & $\begin{array}{l}\text { AAP diagnóstica } \\
\text { AAP } 1^{\circ} \text { bimestre }\end{array}$ \\
\hline & & $\begin{array}{l}\text { Identificar aspectos linguísticos em } \\
\text { funcionamento em um texto. }\end{array}$ & $\begin{array}{l}\text { AAP diagnóstica } \\
\text { AAP } 1^{\circ} \text { bimestre }\end{array}$ \\
\hline
\end{tabular}

Fonte: Elaborado pelas autoras com base nos dados da PFA. 
Para o planejamento e realização da primeira intervenção junto às três turmas de $6^{\circ}$ ano, consideramos a análise dos resultados das duas avaliações iniciais, sistematizados no Quadro 5, bem como a ideia de que, no ensino da língua portuguesa, as práticas de leitura, de produção oral e escrita e de análise linguística devem ser realizadas em sala de aula de maneira integrada, por meio do estudo de textos autênticos que circulam socialmente (APARÍCIO, 2010; GONÇALVES, 2011). Tendo isso em vista, optamos por utilizar o dispositivo da sequência didática (SD) de gêneros textuais, proposto por pesquisadores da Universidade de Genebra (DOLZ; SCHNEUWLY, 2004).

O trabalho com a SD, entendida como "[...] um conjunto de atividades escolares organizadas, de maneira sistemática, em torno de um gênero textual oral ou escrito” (DOLZ; SCHNEUWLY, 2004, p. 97), permite a criação, em sala de aula, de situações reais e concretas de produção e leitura de textos, com atenção às situações de interação entre produtores e receptores, bem como aos recursos linguísticos utilizados na produção do texto, de acordo com a situação comunicativa proposta. Nesse sentido, o trabalho com a SD permite ao professor promover, de forma integrada e contextualizada, as diferentes práticas de uso e reflexão sobre a língua portuguesa. Além disso, por evidenciar as capacidades de linguagem dos alunos, permite uma diferenciação do ensino, favorecendo a elaboração de projetos (ZUCATELLI, 2017).

Na intervenção, ${ }^{2}$ seguimos o modelo proposto por Dolz e Schneuwly (2004, p. 98), conforme a Figura 1 abaixo.

\section{FIGURA 1 - Etapas de uma sequência didática}

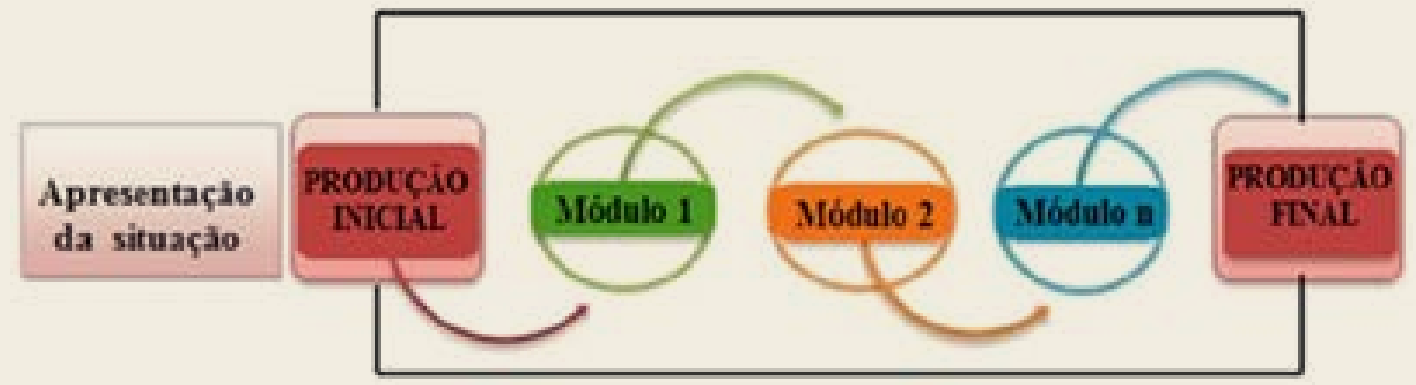

Fonte: Adaptado de Dolz, Noverraz e Schneuwly, (2004, p. 83).

Para o desenvolvimento da SD, na primeira intervenção, optamos pelo gênero fábula, por ser sugerido pelo CLP para o $6^{\circ}$ ano e por ser um típico gênero narrativo que, com estrutura simples, permite o estudo e a compreensão dos elementos da narrativa e seus recursos. Além disso, quanto ao conteúdo, as fábulas podem

2 Não apresentamos detalhadamente o processo e os dados das intervenções realizadas por meio da SD, visto que esse não é o foco principal neste artigo. 
conduzir os alunos a uma reflexão sobre os comportamentos humanos e análise de problemas do cotidiano, pois os acontecimentos presentes nas fábulas consistem em situações e aspectos da vida apresentados de forma representativa e que podem fazer com que o leitor se identifique ao ler (FERNANDES, 2001).

Segundo Dolz, Gagnon e Decândio (2010), o primeiro passo para elaboração da SD é a construção do modelo didático do gênero, processo que exige do professor o domínio dos conteúdos que serão ensinados para melhor seleção de aspectos do gênero a ser trabalhado. Os autores apresentam três dimensões básicas desse modelo: 1) os saberes de referência a serem mobilizados pelo professor para trabalhar com um gênero, os quais darão a base para compreender seu funcionamento; 2) a descrição dos diferentes componentes textuais específicos do gênero: situação de comunicação, conteúdos temáticos, modos de construção composicional e estilo; 3) capacidades de linguagem dos alunos identificadas e observadas nas diferentes situações de ensino e aprendizagem em sala de aula.

Sendo assim, para planejarmos a SD do gênero fábula, realizamos estudos na literatura a respeito desse gênero, consultamos trabalhos que já o investigaram e analisaram e realizamos a leitura de várias fábulas de diferentes fontes e estilos. Com essa tarefa, destacamos os conteúdos típicos do gênero, as variadas formas de organização dos textos que pertencem a esse gênero e o estilo, características linguísticas e seus efeitos, escolhas lexicais, entre outros aspectos linguísticos e discursivos das fábulas.

Outro elemento essencial no processo do planejamento da SD é a elaboração de uma grade de análise que forneça procedimentos mais claros e precisos para as avaliações das produções escritas dos alunos. Sendo assim, com base na proposta de Dolz, Gagnon e Decândio (2010), elaboramos uma grade de análise do gênero fábula para avaliar as produções dos alunos. Após essa estruturação, demos início ao desenvolvimento da SD em sala de aula, seguindo as etapas ilustradas na Figura 1.

Iniciamos com a apresentação da situação, construindo colaborativamente com os alunos a situação de comunicação que envolve o gênero abordado: a produção de fábulas, tendo como objetivo propiciar aos alunos do $4^{\circ}$ e $5^{\circ}$ ano uma leitura prazerosa dos textos. Para a circulação dessas produções, seria produzido um livro de fábulas ilustrado e organizado pelos próprios autores - os alunos do $6^{\circ}$ ano.

Na sequência, os alunos realizaram a produção inicial, o momento de conhecer o que realmente sabem, na prática, pois suas produções são como uma "[...] ferramenta fundadora do planejamento à medida que informam as capacidades linguísticas que os alunos já possuem" (ZUCATELLI, 2017, p. 76). Após esse processo, começamos a análise das produções, tendo por referência a grade do gênero fábula. Esse resultado, juntamente com a análise dos resultados da AAP diagnóstica e AAP do primeiro bimestre, orientou-nos na construção dos módulos da SD. 
Foram realizados dez módulos, sendo que cada um foi pensado e estruturado com um objetivo específico, tendo em vista as habilidades defasadas ou que ainda necessitavam de um aprofundamento. Ao término dos módulos, fizemos uma autoavaliação com cada uma das turmas e elaboramos coletivamente uma lista das características do gênero. Depois disso, devolvemos aos alunos a primeira produção para analisarem e realizarem a produção final, conforme o que aprenderam na sequência dos módulos. Após a produção final, os alunos ainda tiveram orientações para revisarem seus textos, para finalmente digitá-los para a confecção dos livros. Pudemos observar, comparando a produção inicial e a final, que os alunos avançaram, ampliando seus conhecimentos de uso da língua escrita, mais especificamente na escrita de textos do gênero fábula, que exige o domínio de recursos linguísticos da tipologia narrativa.

Outra estratégia importante que utilizamos ao longo dessa primeira intervenção foi a organização dos alunos em agrupamentos produtivos, isto é, organizamos a turma em grupos ou duplas de alunos que apresentavam o domínio de habilidades diferentes. Os agrupamentos devem ter como base o conhecimento que os alunos já dominam e, a partir disso ajustar a uma tarefa. O professor pode, por exemplo, "[...] agrupar alunos que já possuem maior domínio de leitura de um tipo de texto com aqueles que precisam se apropriar de suas características” (SÃO PAULO, s.d., p. 12).

De fato, os agrupamentos produtivos são uma importante estratégia, porque fornecem a troca mútua de informações entre os alunos, que oferecem contribuições e, numa atitude conjunta de colaboração, buscam realizar as atividades propostas da melhor maneira. Para agrupar os alunos do $6^{\circ}$ ano, extraímos dados da PFA relativos ao desempenho individual por aluno em cada uma das habilidades contempladas nas provas AAP diagnóstica e AAP do primeiro bimestre.

Todo esse processo refletiu positivamente nos resultados da AAP do segundo bimestre, realizada em agosto de 2018, após a primeira intervenção, tendo por referência a MAP do segundo bimestre do $6^{\circ}$ ano. A avaliação foi composta por 12 questões (4 consideradas de nível fácil, 4 de nível médio e 4 de nível difícil) contemplando 6 habilidades, sendo 2 questões, de níveis diferentes, para cada habilidade. Os gêneros dos textos-base das questões foram fábula, música, crônica e tirinha, como apresentado no Quadro 6 a seguir. 


\section{QUADRO 6 - Desempenho na AAP do segundo bimestre}

\begin{tabular}{|c|c|c|c|c|}
\hline HABILIDADE & QUESTÃO & NÍVEL & GÊNERO & ACERTOS \\
\hline \multirow{2}{*}{$\begin{array}{l}\text { Identificar o uso adequado dos modos verbais (indicativo, } \\
\text { subjuntivo e imperativo) em funcionamento no texto. }\end{array}$} & Q8 & Difícil & Música & $48 \%$ \\
\hline & Q11 & Difícil & Música & $47 \%$ \\
\hline \multirow{2}{*}{$\begin{array}{l}\text { Reconhecer os efeitos de sentido produzidos pelo uso de } \\
\text { conotação ou denotação em um texto. }\end{array}$} & Q3 & Médio & Música & $43 \%$ \\
\hline & Q10 & Difícil & Música & $49 \%$ \\
\hline \multirow{2}{*}{$\begin{array}{l}\text { Inferir informação implícita (opinião ou tema/assunto } \\
\text { principal) em um texto. }\end{array}$} & Q1 & Fácil & Fábula & $68 \%$ \\
\hline & Q7 & Médio & Crônica & $72 \%$ \\
\hline \multirow{2}{*}{ Reconhecer traços característicos de um texto. } & Q2 & Fácil & Música & $80 \%$ \\
\hline & Q9 & Médio & Música & $67 \%$ \\
\hline \multirow{2}{*}{$\begin{array}{l}\text { Reconhecer os elementos da narrativa (personagem, } \\
\text { enredo, tempo, espaço ou foco narrativo) em um texto. }\end{array}$} & Q6 & Médio & Crônica & $73 \%$ \\
\hline & Q5 & Difícil & Crônica & $29 \%$ \\
\hline \multirow{2}{*}{$\begin{array}{l}\text { Localizar itens de informação explícita, distribuídos ao } \\
\text { longo do texto. }\end{array}$} & Q4 & Fácil & Crônica & $81 \%$ \\
\hline & Q12 & Fácil & Tirinha & $81 \%$ \\
\hline
\end{tabular}

Fonte: Elaborado pelas autoras com base nos dados da PFA.

Como podemos observar no Quadro 6, em geral, os alunos tiveram um bom desempenho (entre 68\% e 81\%) em todas as questões de nível fácil na maioria das habilidades solicitadas na prova. O mesmo ocorre com as habilidades de nível médio, em que os alunos tiveram desempenho entre $67 \%$ e $73 \%$, com exceção da questão 3 (43\%), cuja habilidade é "Reconhecer os efeitos de sentido produzidos pelo uso de conotação ou denotação em um texto", o que envolve a realização de inferência, uma estratégia complexa de leitura, em que os alunos apresentam muita dificuldade.

Nas questões de nível difícil, os alunos tiveram uma média entre 29\% e 49\%. A habilidade com pior desempenho, novamente, foi "Reconhecer os elementos da narrativa (personagem, enredo, tempo, espaço ou foco narrativo) em um texto" (questão 5). Essa habilidade também foi solicitada nas AAP diagnóstica e do primeiro bimestre, e nos questionamos sobre, após o processo de intervenção em que trabalhamos intensamente com os elementos da narrativa, a habilidade não ter avançado e até mesmo ter retrocedido em 20\%. Novamente, recorremos à PFA para entender o que havia acontecido. Na segunda AAP, os gêneros textuais foram diferentes (letra de música, crônica e tirinha), e isso pode ter refletido no resultado. Observamos também que, nessa AAP, o elemento da narrativa focalizado na questão é o "enredo". Na AAP do primeiro bimestre, o elemento da narrativa solicitado na questão foi o "tempo", um elemento mais fácil de ser identificado. E esse pode ser outro aspecto que explica o baixo desempenho nessa habilidade na segunda AAP.

Em síntese, considerando os resultados da AAP do segundo bimestre, pudemos verificar que as dificuldades dos alunos estão centradas em apenas duas categorias (ver Quadro 5), a saber: inferência e análise linguística/gramática contextualizada. Os alunos avançaram em relação às dificuldades apresentadas anteriormente no Quadro 5, que eram em quatro categorias. 
Tendo isso em vista, e o fato de os alunos terem apresentado baixo desempenho em questões cujo texto-base era uma crônica, optamos por planejar a segunda intervenção, com uma SD para o trabalho com esse gênero textual. Novamente, antes mesmo de iniciar a intervenção, com a ajuda da PFA, fizemos outra análise do desempenho individual de cada aluno, por habilidade, para montarmos novos agrupamentos produtivos.

Para a segunda intervenção, continuamos, então, a utilizar o dispositivo da SD, proposto pelos pesquisadores da Universidade de Genebra (DOLZ; SCHNEUWLY, 2004), enfatizando o trabalho com os recursos expressivos da língua e os elementos da narrativa, mantendo a articulação de atividades de leitura, produção textual e análise linguística.

Da mesma forma, para planejarmos a SD de crônica, realizamos estudos na literatura a respeito desse gênero, buscamos pesquisas que já o investigaram e analisaram e realizamos a leitura de várias crônicas, inclusive tendo por referência o material utilizado pela rede estadual paulista, denominado "Escrevendo o Futuro", ${ }^{3}$ que segue as orientações do Grupo de Genebra, especialmente de Joaquim Dolz, um dos inspiradores desse programa. A partir desse estudo, também elaboramos uma grade para a análise das produções inicial e final dos alunos.

Seguindo os pressupostos e as etapas da SD, construímos em conjunto com as turmas a situação comunicativa para a produção: a construção de um blog de crônicas, tendo como leitores-alvo os alunos do curso de Pedagogia de uma universidade da região, com o objetivo de entreter e/ou levar o leitor a refletir sobre situações/ fatos da vida cotidiana narrados por alunos de $6^{\circ}$ ano, com idade entre 11 e 13 anos.

Após essa segunda intervenção, os alunos realizaram a terceira AAP, com os conteúdos e as habilidades referentes ao terceiro bimestre do $6^{\circ}$ ano. A avaliação foi composta por 12 questões (4 consideradas de nível fácil, 4 de nível médio e 4 de nível difícil), contemplando 6 habilidades. Os gêneros dos textos-base das questões foram: miniconto, conto, crônica e notícia. O Quadro 7, a seguir, mostra os resultados dessa AAP.

3 Criado em 2002 pela Fundação Itaú Social, com coordenação técnica do Centro de Estudos e Pesquisas em Educação, Cultura e Ação Comunitária (Cenpec), contribui para a melhoria do ensino da leitura e escrita nas escolas públicas de todo o país. Realiza a Olimpíada de Língua Portuguesa Escrevendo o Futuro, desenvolvida em parceria com o Ministério da Educação. 


\section{QUADRO 7 - Desempenho na AAP do terceiro bimestre}

\begin{tabular}{|c|c|c|c|c|}
\hline HABILIDADE & QUESTÃO & NÍVEL & GÊNERO & ACERTOS \\
\hline \multirow{2}{*}{$\begin{array}{l}\text { Identificar aspectos linguísticos (substantivo, adjetivo, } \\
\text { verbo e advérbio) em funcionamento em um texto. }\end{array}$} & Q12 & Difícil & Notícia & $38 \%$ \\
\hline & Q5 & Difícil & Notícia & $40 \%$ \\
\hline \multirow{2}{*}{$\begin{array}{l}\text { Estabelecer relações de causa e consequência entre } \\
\text { partes e/ou elementos de um texto. }\end{array}$} & Q9 & Médio & Conto & $71 \%$ \\
\hline & Q1 & Médio & Crônica & $65 \%$ \\
\hline \multirow{2}{*}{$\begin{array}{l}\text { Reconhecer aspectos linguísticos (pontuação) em } \\
\text { funcionamento em um texto. }\end{array}$} & Q8 & Fácil & Miniconto & $72 \%$ \\
\hline & Q11 & Difícil & Notícia & $37 \%$ \\
\hline \multirow{2}{*}{$\begin{array}{l}\text { Inferir informação implícita (opinião ou tema/assunto } \\
\text { principal) em um texto. }\end{array}$} & Q7 & Fácil & Miniconto & $76 \%$ \\
\hline & Q10 & Difícil & Conto & $60 \%$ \\
\hline \multirow{2}{*}{$\begin{array}{l}\text { Localizar itens de informação explícita, distribuídos ao } \\
\text { longo do texto. }\end{array}$} & Q4 & Fácil & Notícia & $84 \%$ \\
\hline & Q3 & Médio & Crônica & $63 \%$ \\
\hline \multirow{2}{*}{$\begin{array}{l}\text { Reconhecer os elementos da narrativa (personagem, } \\
\text { enredo, tempo, espaço ou foco narrativo) em um texto. }\end{array}$} & Q6 & Fácil & Miniconto & $89 \%$ \\
\hline & Q2 & Médio & Crônica & $64 \%$ \\
\hline
\end{tabular}

Fonte: Elaborado pelas autoras.

Os resultados mostraram evolução em todos os níveis, pois, nas questões de nível fácil, mais de $70 \%$ dos alunos dominam as quatro habilidades; de nível médio, mais de 60\%; e, de nível difícil, tiveram uma variação de 37\% a 60\%. Mesmo no nível difícil, que ainda tem um percentual baixo, houve evolução, pois, se considerarmos a habilidade "Identificar aspectos linguísticos (substantivo, adjetivo, verbo e advérbio) em funcionamento em um texto", na AAP do primeiro bimestre, o resultado foi de 17\% no nível difícil e passou a ser entre 38\% e 40\% na AAP do terceiro bimestre.

Já quanto à habilidade "Reconhecer aspectos linguísticos (pontuação) em funcionamento em um texto", não podemos mensurar ao certo a evolução no nível difícil, uma vez que tal habilidade apareceu apenas em questão de nível difícil na AAP do terceiro bimestre. Mesmo assim, pelo que pudemos verificar nesse resultado, houve um avanço, pois os alunos apresentaram dificuldades nas questões que envolviam aspectos linguísticos e pontuação em questões consideradas difíceis, mas essa mesma habilidade avançou 2\% em relação a AAP do primeiro bimestre em questão de nível fácil.

A análise dos resultados da AAP do terceiro bimestre, realizada após a SD de crônica narrativa (segunda intervenção), mostra que os alunos apresentaram maior dificuldade em habilidades de apenas uma categoria: análise linguística/gramática contextualizada (ver Quadro 5).

Outro ponto que pudemos identificar, ao analisar as questões da AAP do terceiro bimestre, é que, nas questões de nível difícil, o gênero solicitado foi notícia, que ainda não havia sido trabalhado com os alunos no $6^{\circ}$ ano. Não houve baixo desempenho nas questões de outros gêneros narrativos.

Em síntese, a AAP do terceiro bimestre mostrou que em todos os níveis de questões houve um avanço, pois o desempenho dos alunos em questões de nível fácil está 
entre 72\% e 89\%; nas de nível médio, entre 63\% e 71\%; e, nas de nível difícil, entre $37 \%$ e $60 \%$. Houve evolução de $4 \%$ nas questões de nível fácil, 5\% nas questões de nível médio e $20 \%$ nas de nível difícil.

É importante lembrar que, nas análises de desempenho das AAP do primeiro e do segundo bimestre, os alunos apresentaram maiores dificuldades justamente nas questões de nível difícil e, portanto, foram essas as habilidades que apresentaram menor percentual de desempenho. Esses dados foram fundamentais para elaborarmos as duas SD (fábula e crônica), pois essas habilidades foram o foco principal das intervenções e, de fato, foi nelas que se observou evolução mais significativa. Com as demais habilidades, a proposta era de aprofundá-las, o que também ocorreu, conforme o percentual de evolução apontado nos Quadros 4, 6 e 7.

\section{CONCLUSÕES}

Neste artigo, nosso principal objetivo foi evidenciar contribuições do uso da Plataforma Foco Aprendizagem para o trabalho do professor de Língua Portuguesa e o melhor desempenho dos alunos dos anos finais do ensino fundamental na rede estadual paulista. Para atingir tal objetivo, traçamos um percurso que articula teoria e prática docente.

Inicialmente, destacamos as concepções de linguagem e de ensino de língua portuguesa que orientam o currículo oficial paulista dessa disciplina, bem como caracterizamos duas ações implantadas recentemente pela SEE-SP - Avaliação da Aprendizagem em Processo e Plataforma Foco Aprendizagem -, tendo em vista a melhoria da qualidade do ensino na rede e nos índices de desempenho em Língua Portuguesa e Matemática da rede estadual.

Por meio de procedimentos metodológicos da pesquisa aplicada, realizada na própria prática da professora pesquisadora em três turmas de $6^{\circ}$ ano, ao longo de três bimestres letivos, realizando a análise e interpretação dos dados da Plataforma e utilizando o dispositivo sequência didática, proposto pelos pesquisadores da Universidade de Genebra, mostramos que o professor pode fazer diagnósticos pontuais das dificuldades dos alunos e, a partir disso, planejar e realizar intervenções mais direcionadas para determinada turma, bem como agrupamentos produtivos tomando por base as habilidades já dominadas e as habilidades em defasagem.

Ressaltamos a importância da PFA para o trabalho do professor de Língua Portuguesa, apontando a funcionalidade e as contribuições desse recurso para a interpretação das informações e tomada de decisões didático-pedagógicas para a melhoria das aprendizagens dos alunos. A Plataforma, como evidenciamos aqui, permite análise e acompanhamento individualizado dos alunos, o que torna muito mais assertivo e produtivo o trabalho do professor. Sem esse recurso, o acompanhamento 
individualizado do rendimento do aluno seria muito mais difícil, diante de tantas atribuições que o professor tem em seu dia a dia.

A PFA também contribui com o desenvolvimento profissional do professor, pois se mostrou uma excelente fonte para a investigação e reflexão da/na própria prática. E, como pudemos constatar na evolução das turmas/alunos, ao fazermos uso dessa Plataforma, conseguimos planejar e realizar um ensino mais personalizado (MORAN, s.d.). Além disso, os alunos tiveram mais oportunidades de acompanhar e ter consciência de seu processo de aprendizagem.

\section{REFERÊNCIAS}

APARÍCIO, A. S. M. Modos individuais e coletivos de produzir a inovação no ensino de gramática em sala de aula. Revista Brasileira de Linguística Aplicada, Belo Horizonte, v. 10, n. 4, p. 883-907, 2010.

BAKHTIN, M. M. Marxismo e filosofia da linguagem. São Paulo: Hucitec, 1997.

BAUER, A. Uso dos resultados do Saresp e formação de professores: a visão dos níveis centrais. Estudos em Avaliação Educacional, São Paulo, v. 19, n. 41, p. 483-498, set./dez. 2008.

BERGER FILHO, R. Currículo e competências. Texto de uso restrito, licenciado para uso pela Secretaria de Educação do Estado de São Paulo. s.d. Disponível em: http://www.rededosaber. sp.gov.br/portais/portals/18/arquivos/curriculo_e_competencias_cr.pdf. Acesso em: 11 maio 2019.

BRASIL. Conselho Nacional de Educação. Câmara de Educação Básica. Resolução n. 3, de 26 de junho de 1998. Institui as Diretrizes Curriculares Nacionais para o Ensino Médio. Brasília: MEC, 1998a.

BRASIL. Secretaria de Educação Fundamental. Parâmetros Curriculares Nacionais: terceiro e quarto ciclos do Ensino Fundamental - Língua Portuguesa. Brasília: MEC, 1998b.

BUNZEN, C.; ROJO, R. Livro didático de língua portuguesa como gênero do discurso: autoria e estilo. In: COSTA VAL, M. G.; MARCUSCHI, V. B. (org.). Livros didáticos de língua portuguesa: letramento, inclusão e cidadania. Belo Horizonte: Ceale; Autêntica, 2005. p. 73-117.

CARVALHO, R. Avaliação das provas de interpretação de texto com foco nas habilidades de leitura. 2014. 281 f. Tese (Doutorado em Linguística do Texto e do Discurso) - Faculdade de Letras, Universidade Federal de Minas Gerais, Belo Horizonte, 2014.

COLL, C. Psicología y curriculum. Barcelona: Papeles de Pedagogía; Paidos, 1992.

DOLZ, J.; GAGNON, R.; DECÂNDIO, F. Produção escrita e dificuldades de aprendizagem. Campinas, SP: Mercado das Letras, 2010.

DOLZ, J.; NOVERRAZ, M.; SCHNEUWLY, B. Sequências didáticas para o oral e a escrita: apresentação de um procedimento. In: SCHNEUWLY, B.; DOLZ, J. Gêneros orais e escritos na escola. Campinas, SP: Mercado de Letras, 2004. p. 81-108.

DOLZ, J.; SCHNEUWLY, B. Gêneros orais e escritos na escola. Campinas, SP: Mercado de Letras, 2004.

FERNANDES, M. T. A. S. Trabalhando com gêneros do discurso: fábula. São Paulo: FTD, 2001. 
FINI, M. I. Proposta curricular do estado de São Paulo: Língua Portuguesa. São Paulo: Secretaria de Educação, 2008.

GATTI, B. A. A pesquisa em mestrados profissionais. In: FÓRUM DE MESTRADOS PROFISSIONAIS EM EDUCAÇÃO, 1., 2014, Salvador. Apresentação [...]. Salvador: Uneb, 2014.

GERALDI, J. W. O texto na sala de aula: leitura e produção. 2. ed. Cascavel, PR: Assoeste, 1984.

GONÇALVES, A. V. Gêneros textuais na escola: da compreensão à produção. Dourados, MS: Editora UFGD, 2011.

KOCH, I. V. A coesão textual. São Paulo: Contexto, 2003.

MARCUSCHI, L. A. Produção textual, análise de gêneros e compreensão. São Paulo: Parábola, 2008.

MILIBAND, D. Choice and voice in personalised learning. In: ORGANIZAÇÃO PARA A COOPERAÇÃO E DESENVOLVIMENTO ECONÔMICO. Personalising education. Paris: OECD, 2006. p. 21-30.

MORAN, J. Como transformar nossas escolas: novas formas de ensinar a alunos sempre conectados. s.d. p. 63-87. Disponível em: http://www2.eca.usp.br/moran/wp-content/uploads/2017/08/ transformar_escolas.pdf. Acesso em: 18 ago. 2019.

NASCIMENTO, E. L. (org.). Gêneros textuais: da didática das línguas aos objetos de ensino. São Carlos, SP: Editora Claraluz, 2009.

PACCOLA, R. As representações da equipe escolar frente aos resultados do SARESP, quanto à leitura. 2012. 248 f. Tese (Doutorado em Educação) - Faculdade de Filosofia e Ciências, Universidade Estadual Paulista "Júlio de Mesquita Filho", Marília, SP, 2012.

PEREIRA, S. C. A proposta curricular do estado de São Paulo e a sala de aula como espaço de transformação social. 2011. 197 f. Tese (Doutorado em Geografia Humana) - Faculdade de Filosofia, Letras e Ciências Humanas, Universidade de São Paulo, São Paulo, 2011.

PINTO, M. A avaliação da aprendizagem em processo (AAP): SEE-SP (2011-2016): da proclamação à execução: estudo de caso do programa em uma escola. 2016. 164 f. Tese (Doutorado em Educação Escolar) - Faculdade de Ciências e Letras, Universidade Estadual Paulista "Júlio de Mesquita Filho", Araraquara, SP, 2016.

PONTE, J. P. Investigar a nossa própria prática. In: GRUPO DE TRABALHO E INVESTIGAÇÃO DA ASSOCIAÇÃO DE PROFESSORES DE MATEMÁTICA (ed.). Reflectir e investigar sobre a prática profissional. Lisboa: Associação de Professores de Matemática, 2002. p. 5-28.

PRADO, M. Análise da matriz de competência em uma aplicação real: avaliação da aprendizagem em processo de Língua Portuguesa da Secretaria da Educação do estado de São Paulo. 2016. 84 f. Dissertação (Mestrado Profissional em Letras) - Faculdade de Ciências e Letras, Universidade Estadual Paulista "Júlio de Mesquita Filho", Assis, SP, 2016.

RODRIGUES, R. F. Usos e repercussões de resultados do SARESP na opinião de professores da rede estadual paulista. 2011. 112 f. Dissertação (Mestrado em Educação) - Pontifícia Universidade Católica de São Paulo, São Paulo, 2011.

ROJO, R. Modos de transposição dos PCNs às práticas de sala de aula: progressão curricular e projetos. In: ROJO, R. (org.). A prática de linguagem em sala de aula: praticando os PCNs. Campinas, SP: Mercado de Letras, 2000, p. 27-38. 
SÃO PAULO (Estado). Secretaria da Educação. A organização dos alunos para as situações de recuperação das aprendizagens: uma conversa sobre agrupamentos produtivos em sala de aula. São Paulo: Secretaria da Educação, s.d. Disponível em:

http://www.escoladeformacao.sp.gov.br/portais/Portals/183/repositorios/biblioteca/ Agrupamentos\%20produtivos.pdf. Acesso em: 5 jan. 2019.

SÃO PAULO (Estado). Secretaria da Educação. Matrizes de referência para a avaliação Saresp: documento básico. São Paulo: Secretaria da Educação, 2009.

SÃO PAULO (Estado). Secretaria da Educação. Currículo do estado de São Paulo: Linguagens, Códigos e suas tecnologias: Ensino Fundamental - Ciclo II e Ensino Médio. São Paulo: Secretaria da Educação, 2011.

SÃO PAULO (Estado). Secretaria da Educação. Avaliação da aprendizagem em processo: comentários e recomendações pedagógicas: subsídios para o professor de Língua Portuguesa: $7^{\circ}$ ano $/ 2^{\circ}$ semestre. São Paulo: Secretaria da Educação, 2014.

SÃO PAULO (Estado). Secretaria da Educação. Relatório Pedagógico 2014 - Saresp: Língua Portuguesa. São Paulo: Secretaria da Educação, 2015.

SÃO PAULO (Estado). Secretaria da Educação. Matriz de avaliação processual: língua portuguesa, linguagens; encarte do professor. São Paulo: Secretaria da Educação, 2016.

SILVA, H. M. G. Gestão educacional e sistemas de avaliação: os pressupostos ideológicos do Saresp e a trajetória das avaliações aplicadas entre 1996 e 2005. 2006. 116 f. Dissertação (Mestrado em Educação Escolar) - Faculdade de Ciências e Letras, Universidade Estadual Paulista "Júlio de Mesquita Filho", Araraquara, SP, 2006.

SILVA, V. G. da; GIMENES, N. A. S.; MORICONI, G. M.; LOUZANO, P. Uso da avaliação externa por equipes gestoras e profissionais docentes: um estudo em quatro redes de ensino público. São Paulo: Fundação Carlos Chagas, 2013. (Textos FCC, v. 38).

SOARES, M. Concepções de linguagem e o ensino da Língua Portuguesa. In: BASTOS, N. B. (org.). Lingua Portuguesa: história, perspectivas, ensino. São Paulo: Educ, 1998. p. 53-60.

ZUCATELLI, C. Sequências didáticas e curadoria de informações nas mídias digitais: uma proposta para formação docente. 2017. Dissertação (Mestrado em Educação) - Universidade Municipal de São Caetano do Sul, São Caetano do Sul, SP, 2017.

\section{COMO CITAR ESTE ARTIGO}

SILVA, Dayane Martin; APARÍCIO, Ana Sílvia Moço. Contribuições da Plataforma Foco Aprendizagem no ensino de língua portuguesa. Estudos em Avaliação Educacional, São Paulo, v. 32, e06551, 2021. DOI: https://doi.org/10.18222/eae.v32.6551

Recebido em: 15 MAIO 2019

Aprovado para publicação em: 3 SETEMBRO 2021 